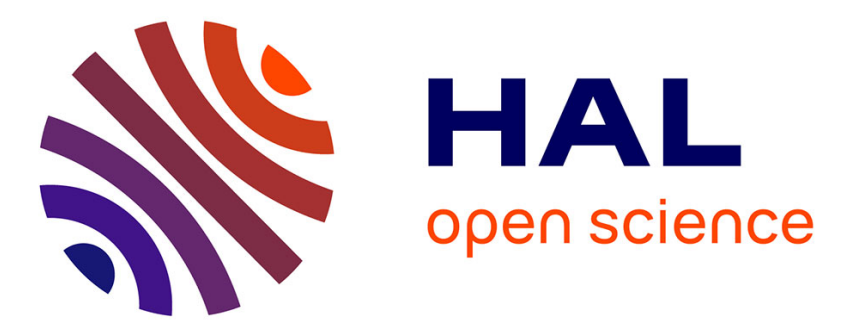

\title{
Statistical Analysis of Current-based Features for Dip Voltage Fault Detection and Isolation
}

\author{
Amel Adouni, Dhia Chariag, Claude Delpha, Demba Diallo, Lassaad Sbita
}

\section{To cite this version:}

Amel Adouni, Dhia Chariag, Claude Delpha, Demba Diallo, Lassaad Sbita. Statistical Analysis of Current-based Features for Dip Voltage Fault Detection and Isolation. 43rd Annual Conference of the IEEE Industrial Electronics Society (IECON 2017), Oct 2017, Beijing, China. 10.1109/iecon.2017.8216748. hal-01578478

\section{HAL Id: hal-01578478}

\section{https://hal-centralesupelec.archives-ouvertes.fr/hal-01578478}

Submitted on 12 Mar 2020

HAL is a multi-disciplinary open access archive for the deposit and dissemination of scientific research documents, whether they are published or not. The documents may come from teaching and research institutions in France or abroad, or from public or private research centers.
L'archive ouverte pluridisciplinaire HAL, est destinée au dépôt et à la diffusion de documents scientifiques de niveau recherche, publiés ou non, émanant des établissements d'enseignement et de recherche français ou étrangers, des laboratoires publics ou privés. 


\title{
Statistical Analysis of Current-based Features for Dip Voltage Fault Detection and Isolation
}

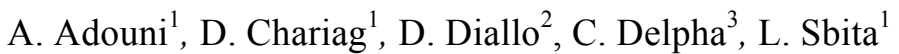 \\ ${ }^{1}$ SPEG Laboratory, ENIG, Gabes, Tunisia, \\ amel.enig@gmail.com \\ ${ }^{2}$ Group of Electrical Engineering Paris, CNRS UMR 8507, CentraleSupelec, Univ. Paris Sud, UPMC, \\ ddiallo@ieee.org \\ ${ }^{3}$ Laboratory of Signals and Systems, CNRS UMR 8506, CentraleSupelec, Univ. Paris Sud, \\ claude.delpha@12s.centralesupelec.fr
}

\begin{abstract}
The high penetration of Wind Turbine (WT) in the grid is a promising solution to increase the electricity production with renewable energies. In this work, we propose a data-driven methodology for dip voltage fault detection and diagnosis. From experimental measurements the current vector trajectory deformation in the $(\alpha \beta)$ reference frame is derived and a statistical-based analysis (first four statistical moments) of two relevant features are extracted (the ratio between the two axis and the rotation angle) is conducted. Thanks to this ratio, the method is robust to load variations. The fault isolation is done accurately with the analysis of the shift angle. The fault detection performances are evaluated with the ROC curves that reveal a probability of detection equal to 1 and a null probability of false alarm.
\end{abstract}

Keywords-Dip voltage fault, Wind Turbine, Current vector, Fault Detection and Identification, Statistical moments, ROC curves.

\section{INTRODUCTION}

According to the collected statistical data, wind energy is one of the fastest growing renewable energy resources [1]. The most optimistic growth scenario estimates that by 2020 , wind farms will supply $2.600 \mathrm{TWh}$ that represents about 11.5-12.3\% of global electricity supply [2]. In many of these wind farms, doubly fed induction generators (DFIG) are used.

Since the wind farms are connected to the grid, an important issue has been discussed in recent years: the dynamic behaviour of WT under different grid conditions. New grid codes have been adopted. Operating under grid fault also known as Low Voltage Ride Through (LVRT) is one of the most important issues [3-6].

Because of the nuisances due to grid fault occurrence the development of a fault detection and isolation (FDI) is mandatory [6].

In the literature the FDI methods can be split in two families: analytical-based methods and data-driven ones using either time-based or time-frequency-based processing approaches of measurements [7-16].

Hereafter a data-driven-based method is proposed. It based on a data history. Actually, it uses the current measurements during a time horizon to extract nonparametric features for fault detection and fault isolation. Using the current vector trajectory in the stationary Concordia 2D reference frame, two relevant features are extracted and analysed for fault detection and isolation. Then, a statistical study is developed. The performances of the method are analysed in terms of sensitivity.

The rest of the paper is organized as follows. In section II, the model of the WT system is briefly presented. In Section III the Fault model is introduced and in Section IV, the fault detection and diagnosis method is detailed. In Section V, experimental results are presented and discussed. A conclusion closes the paper.

\section{WIND TURBINE MODEL}

For a high output power production, the variable speed Wind Turbine (WT) system is chosen in this study. The configuration is displayed in Fig. 1. The stator is connected directly to the grid. The rotor circuit is coupled to the grid via a partial-scale power converter where the type is a back-to-back converter.

According to wind speed change, the kinetic power changes too. As a result, the WT output power varies. In order to maximize the captured power, the tip speed ratio needs to be controlled using a Maximum Power Point Tracking (MPPT) algorithm.

The second is the Machine Side Converter (MSC) control. It controls the electromagnetic torque and the stator reactive power of the Doubly Fed Induction Generator (DFIG). The third block controls the Grid Side Converter (GSC) to regulate the DC bus voltage and the passive R-L filter 
reactive power to zero (unity power factor at the point of connection to the grid).

The details of the modelling can be found in [17].

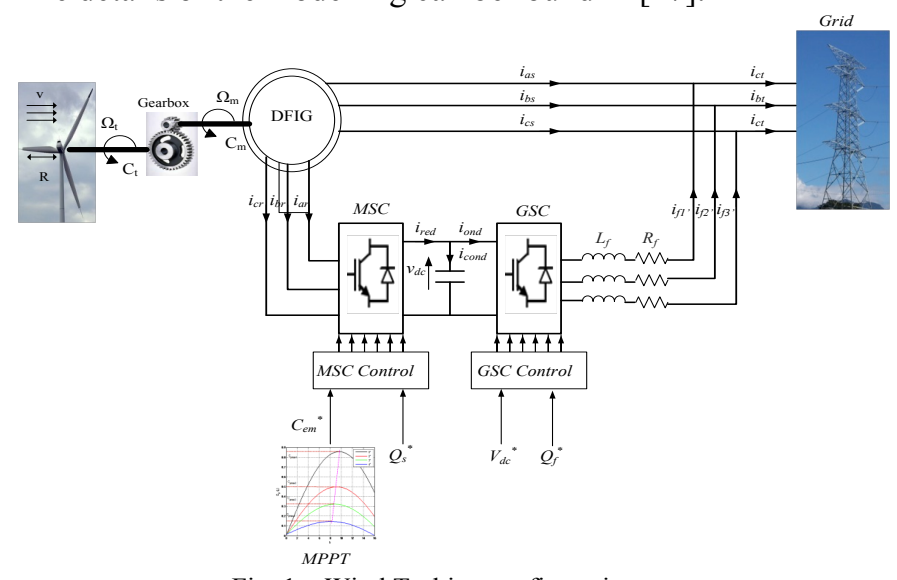

Fig. 1. Wind Turbine configuration.

\section{FAULT DESCRIPTION}

With no loss of generality, the only fault type under study in this paper consists of a dip for one phase while the angle and the two others phases voltage remain unaffected. There are three possible configurations. In the following, only one subtype is described. It is the dip voltage in phase a. The details of the fault modelling can be found in [18].

In dip voltage phases a, the three voltage grid expressions in the time domain are expressed as:

$$
\begin{aligned}
& v_{a}(t)=(1-d) V \sqrt{2} \sin (\omega t) \\
& v_{b}(t)=V \sqrt{2} \sin (\omega t-2 \pi / 3) \\
& v_{c}(t)=V \sqrt{2} \sin (\omega t+2 \pi / 3)
\end{aligned}
$$

Where $d$ is the voltage dip depth $\mathrm{V}$ is the voltage magnitude. The phasor representation is illustrated in Fig. 2.

$\mathrm{e}_{\mathrm{c}}$

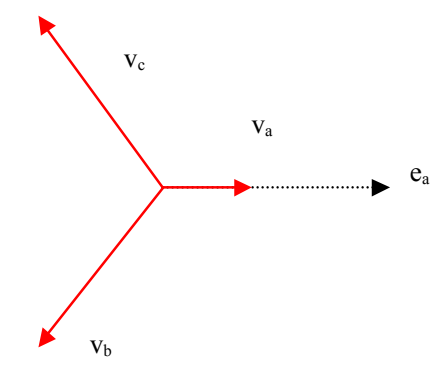

$\mathrm{e}_{\mathrm{b}}$

Fig. 2. Phasor representation in case of dip voltage subtype phase a.

$e_{a}, e_{b}, e_{c}$ are respectively the vector representation in healthy condition.

\section{FAULT DETECTION AND IDENTIFICATION}

\section{1) The procedure}

Fig. 3 illustrates the WT current vector trajectory in the $(\alpha \beta)$ stationary reference frame. It is observed that in faulty case, the trajectory rotates and changes from a circle to an ellipse. The Fault Detection and Identification (FDI) procedure is based on the extraction and the analysis of the features (the ratio between the two axes and the shift angle).

Let's note $\left(i_{\alpha}\left(t_{1}\right), i_{\beta}\left(t_{1}\right)\right)$ and $\left(i_{\alpha}\left(t_{2}\right), i_{\beta}\left(t_{2}\right)\right)$ the WT currents in $\alpha \beta$ reference frame measured respectively at time instants $t_{1}$ and $t_{2} \cdot O \vec{A}$ is the vector defined with $\left(i_{\alpha}\left(t_{1}\right)\right.$, $\left.i_{\beta}\left(t_{1}\right)\right)$ and $O \vec{B}$ is the vector defined with $\left(i_{\alpha}\left(t_{2}\right), i_{\beta}\left(t_{2}\right)\right)$. In healthy conditions, the ratio $R=\left\|\frac{O \vec{A}}{\overrightarrow{O B}}\right\|$ is equal to 1 since the trajectory is a circle.

At fault occurrence the ratio $\mathrm{R}$ deviates from 1 and the trajectory shifts from its initial position. The ratio $\mathrm{R}$ under healthy function and a dip voltage phase a is illustrated in the Fig. 4.

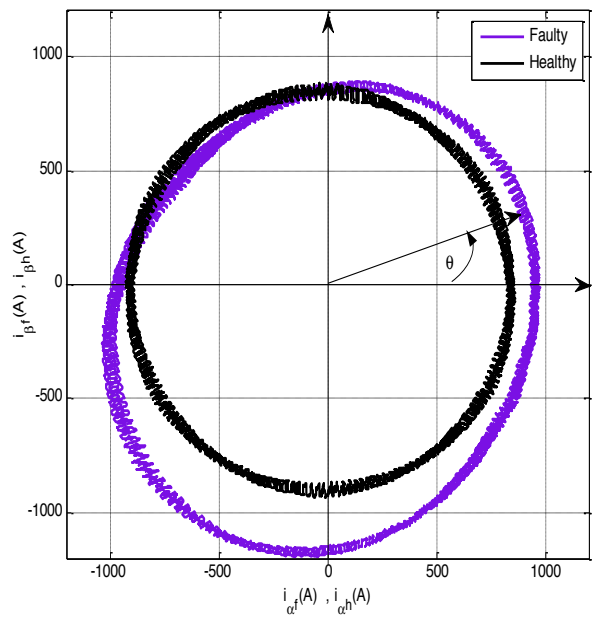

Fig. 3. Current vector trajectory in $\alpha \beta$ reference frame in healthy and faulty conditions.

Therefore the ratio $R$ and the shifting angle $\theta$ will be the features used for fault detection and fault isolation as it can be seen in Table I.

TABLE I. FAULT SUBTYPES IDENTIFICATION

\begin{tabular}{|c|c|}
\hline $\boldsymbol{\theta}$ & Fault subtype \\
\hline$\pi / 2$ or $-\pi / 2$ & $\mathrm{~b} \& \mathrm{c}$ \\
\hline$] 0, \pi / 2[$ or $]-\pi,-3 \pi / 2[$ & $\mathrm{a} \& \mathrm{c}$ \\
\hline$] \pi / 2, \pi[$ or $]-3 \pi / 2,-2 \pi[$ & $\mathrm{a} \& \mathrm{~b}$ \\
\hline
\end{tabular}




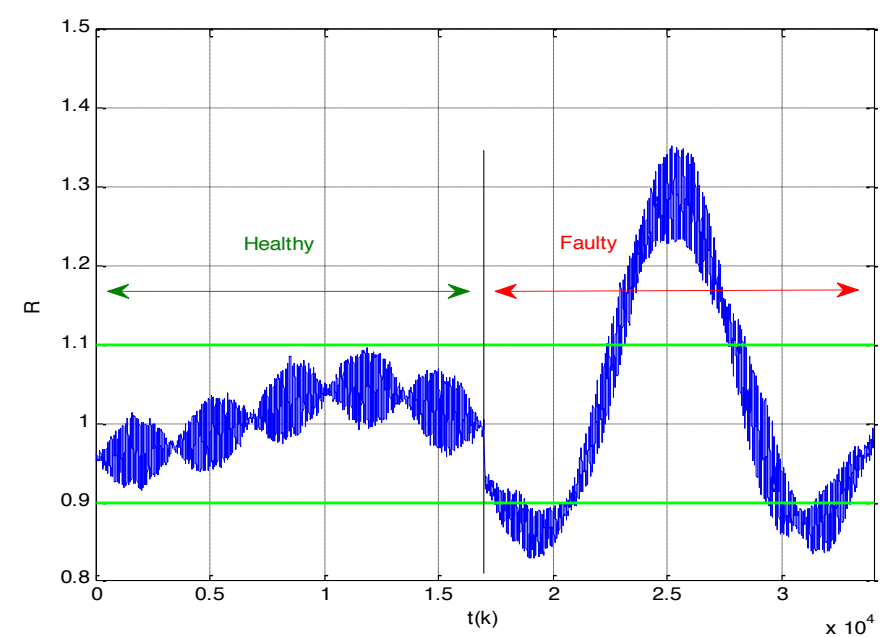

Fig. 4. Evolution of the ratio R under fault B subtype a.

\section{Performance eVAluation Results}

\section{1) Feature analysis}

If we assume a random discrete variable $X=\left(x_{1}, \ldots, x_{j}, \ldots, x_{N}\right)$ of $\mathrm{N}$ samples, let us first recall the following definitions :

$\mu=\frac{1}{N} \sum_{1}^{N} x_{j}$ the mean value, measures the center of the data distribution, $\sigma^{2}=\frac{1}{N} \sum_{1}^{N}\left(x_{j}-\mu\right)^{2}$ the variance measures the dispersion within the data dispersion, $S k w=\frac{1}{N} \sum_{1}^{N}\left(\frac{x_{j}-\mu}{\sigma}\right)^{3}$

the skewness measures the dissymetry of the data distribution and $K u r=\frac{1}{N} \sum_{1}^{N}\left(\frac{x_{j}-\mu}{\sigma}\right)^{4}$ the kurtosis measures the flatness of the data distribution.

In order to compare the four statistical moments efficiency a sensitivity index is computed as follows:

Sensitivity $=\frac{\left\langle C_{r}>_{\text {faulty }}-<C_{r}\right\rangle_{\text {healthy }}}{\operatorname{Max}\left(C_{r}-<C_{r}>\right)_{\text {healthy }}}$

where $C_{r}$ stands for the mean value, the variance, the skewness or the kurtosis and $\left\langle C_{r}\right\rangle$ is the mean value [19]. For each subtype, 200 realisations are realised (the first 100 for the healthy case and the last 100 for the faulty case).

The first four statistical moments of the ratio $\mathrm{R}$ for the three subtypes $(\mathrm{a}, \mathrm{b}, \mathrm{c})$ are respectively plotted on Figs. 5, 6, 7.

The sensitivity for the first four statistical moments for the three subtypes is calculated and presented in Tables II, III and IV.
From the values in Table II, we can conclude for this level of dip voltage fault that the first four statistical moments can be used as fault indicator with a threshold set to $\operatorname{Max}\left(C_{r}-<C_{r}>\right)_{\text {healthy }}$.

TABLE II. SENSITIVITY INDEXES FOR THE FOUR CRITERIA
\begin{tabular}{|l|c|c|c|c|}
\hline & Mean & Variance & Skewness & Kurtosis \\
\hline Sensitivity & $3.2465 \mathrm{e}+02$ & $9.7706 \mathrm{e}+03$ & $2.5214 \mathrm{e}+02$ & 96.1973 \\
\hline$P_{M D}$ & 0 & 0 & 0 & 0 \\
\hline
\end{tabular}

We can also derive from this table that the variance is the most sensitive feature for fault subtype a.
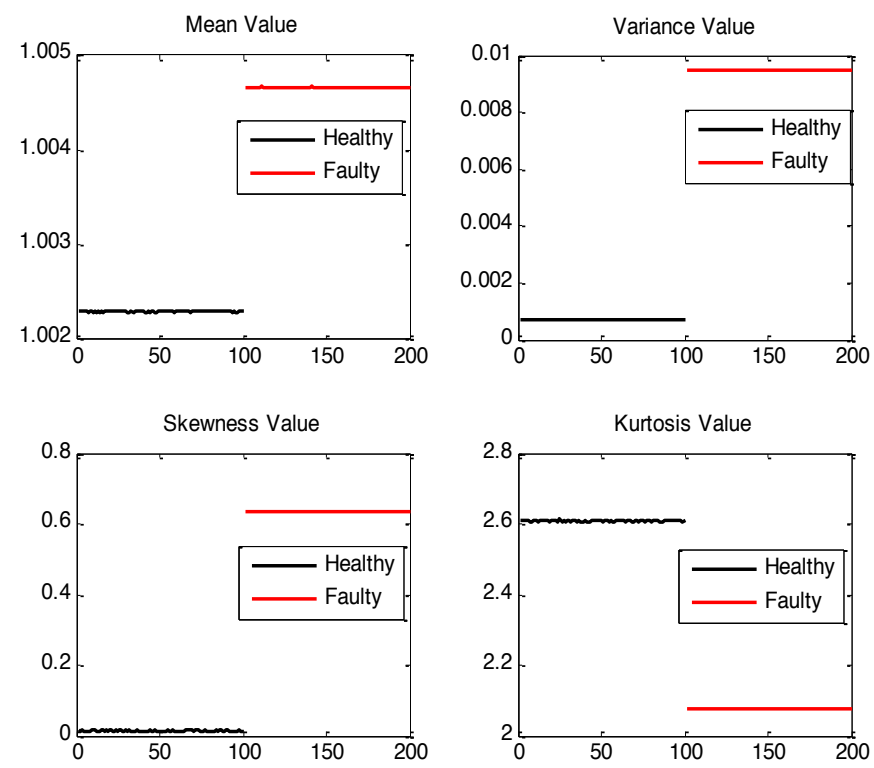

Fig. 5. First four statistical moments for fault subtype a.

\begin{tabular}{|c|c|c|c|c|}
\hline & Mean & Variance & Skewness & Kurtosis \\
\hline Sensitivity & $1.60176 \mathrm{e}+03$ & $5.6997 \mathrm{e}+03$ & 4.2407 & $1.1208 \mathrm{e}+02$ \\
\hline$P_{M D}$ & 0 & 0 & 0 & 0 \\
\hline
\end{tabular}

From the sensitivity values in Table III, the first four statistical moments are relevant features for subtype fault $b$ dip voltage.

The variance is still the most sensitive feature. 

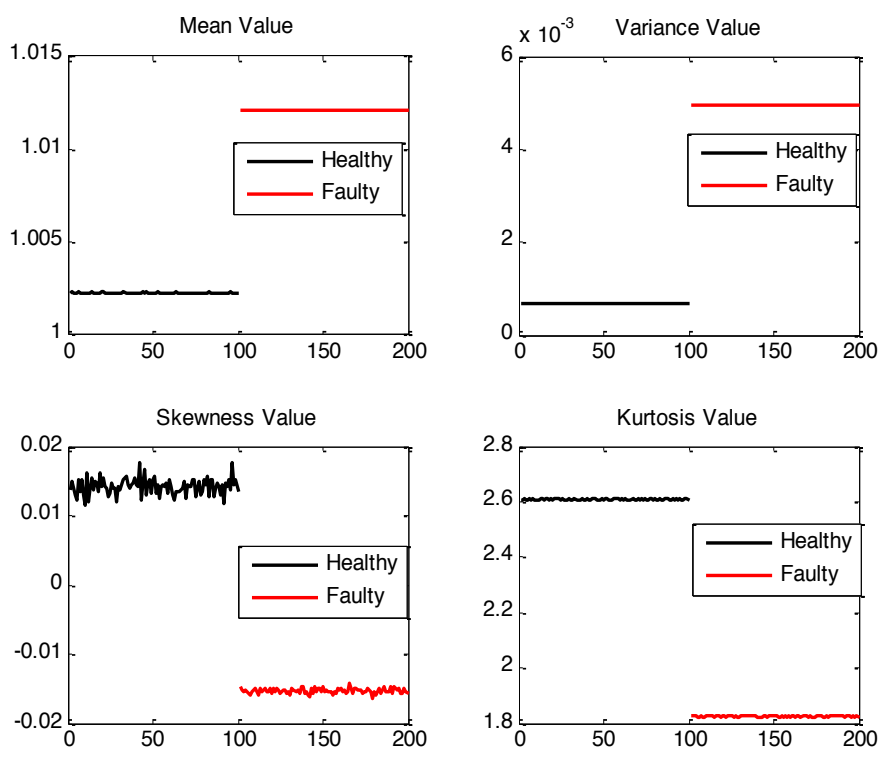

Fig. 6. First four statistical moments for fault subtype b.
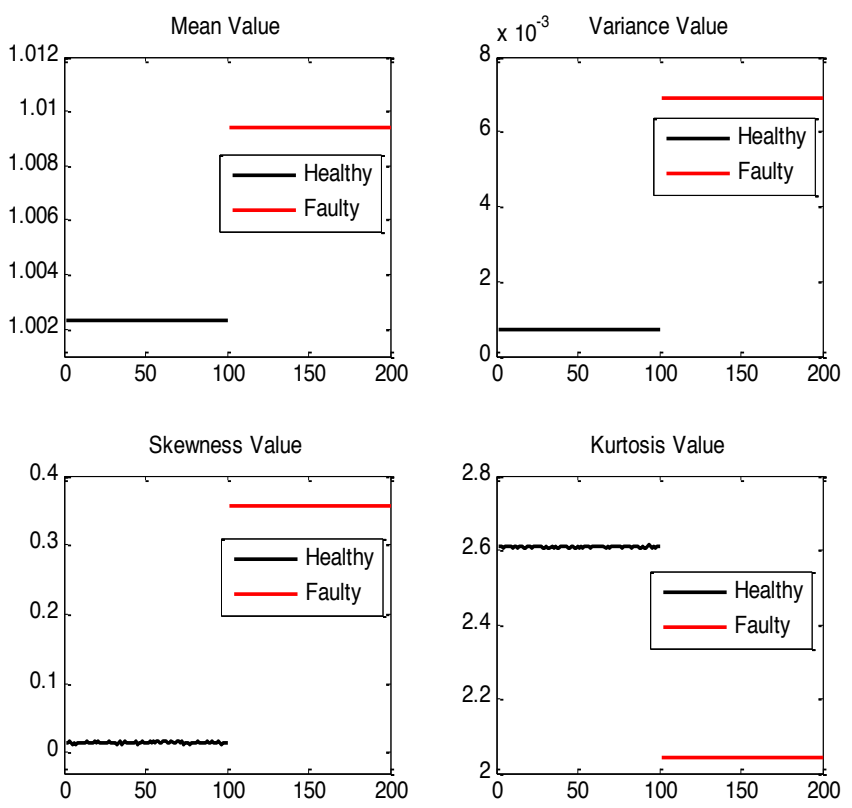

Fig. 7. First four statistical moments for subtype phase c.

In Table IV, the sensitivity indexes for all the four criteria are very high. Therefore each of them can be used as an efficient fault detector. However the variance, with the highest sensitivity, would be the most relevant feature for fault detection.

TABLE IV. SENSITIVITY INDEXES FOR THE FOUR CRITERIA
\begin{tabular}{|l|c|c|c|c|}
\hline & Mean & Variance & Skewness & Kurtosis \\
\hline Sensitivity & $1.4431 \mathrm{e}+03$ & $6.0971 \mathrm{e}+03$ & $1.208 \mathrm{e}+02$ & $1.0071 \mathrm{e}+02$ \\
\hline$P_{M D}$ & 0 & 0 & 0 & 0 \\
\hline
\end{tabular}

In order to evaluate the fault detection performances, the probalities of fault detection $\left(P_{D}=1-P_{M D}\right)$ and false alarms $\left(P_{F A}\right)$ are computed and the ROC curves are plotted in Figs. 8, 9, 10.

The analysis of these curves shows very good performances with $P_{D}=1$ and $P_{F A}=0$.

As a consequence, the setting of the fault detection threshold to $\operatorname{Max}\left(C_{r}-<C_{r}>\right)_{\text {healthy }}$ is relevant. This value is easily obtained during healthy operation with a reasonable computational burden.
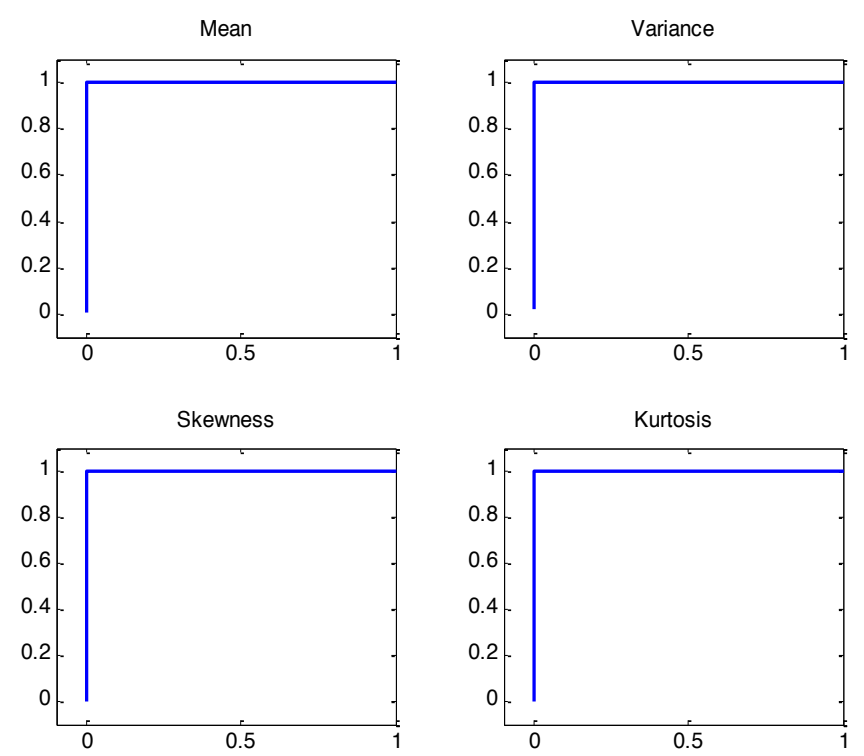

Fig. 8. ROC curves for the first four statistical moments in case of subtype phase a.
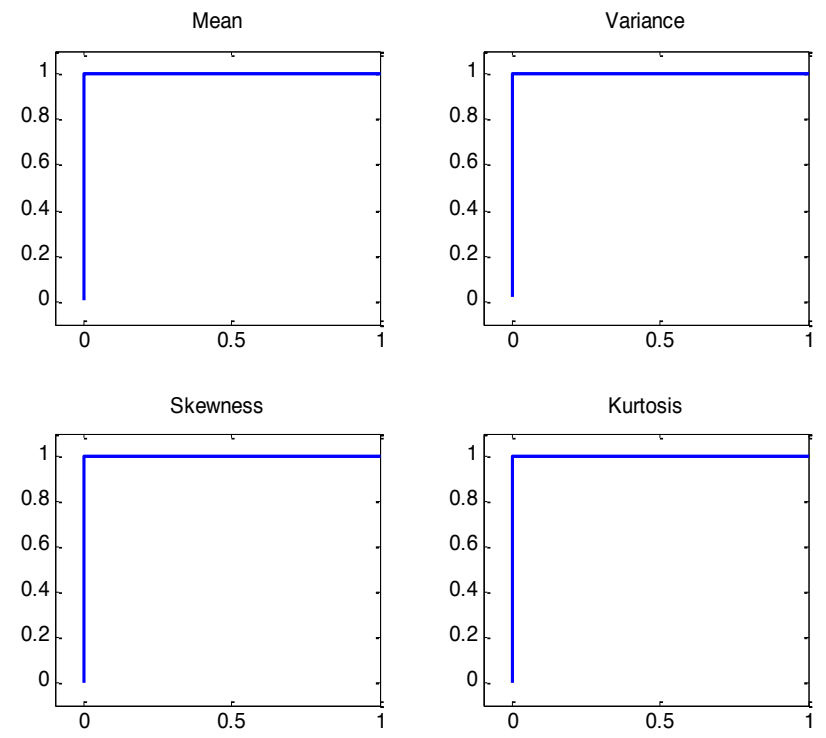

Fig. 9. ROC curves for the first four statistical moments in case of subtype phase b. 

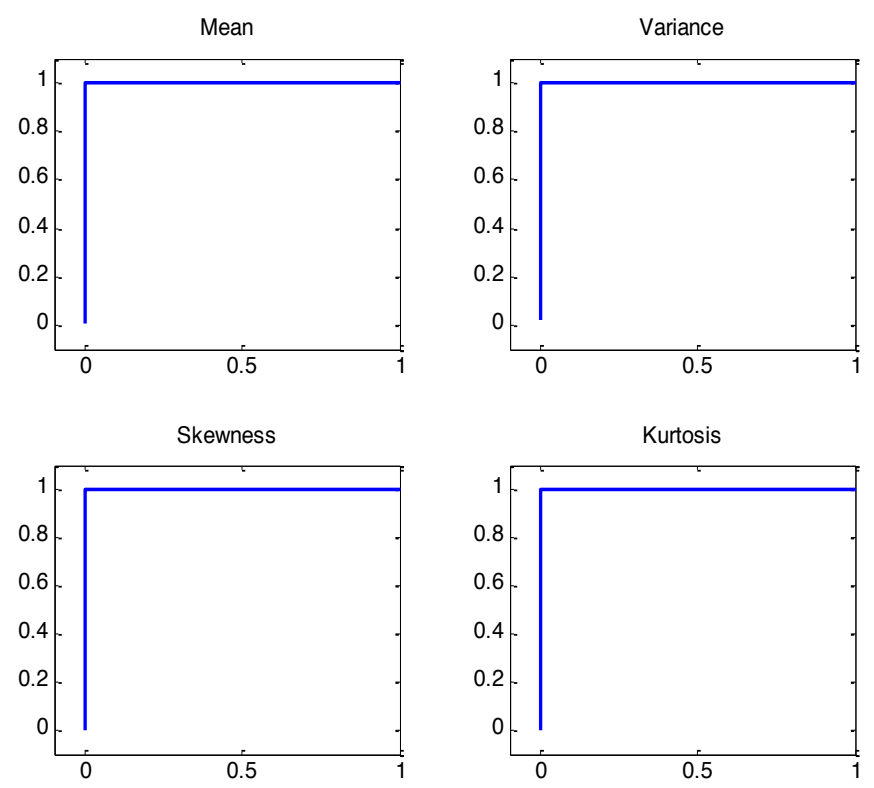

Fig. 10. ROC curves for the first four statistical moments in case of subtype phase c.

\section{CONCLUSION}

In this paper, we have proposed a dip voltage fault detection and isolation method for Wind Energy Conversion System. The method is based on a data-driven modelling using the measured line currents and the relevant features are extracted from the current vector trajectory deformation in the Concordia reference frame. From the analysis of the first four statistical moments, it has been shown that the three fault subtypes can be detected reliably with the first and second statistical moments (respectively the mean value and the variance). In fact they exhibit the highest sensitivity values guaranteeing very good fault detection performances. This is confirmed with the ROC curves. The other two statistical moments (skewness and kurtosis) are less sensitive to the fault.

\section{REFERENCES}

[1] F. EM, H. Zadeh, N. Ektesabi; "Comparison of fault-ride-through capability of dual and single-rotor wind turbines", Renewable Energy, 48(2012) pp. 473-481.

[2] S. Slim, V. Lieshout, P. P. Asanka, et al; "Determination of the combined vibration a land acoustic emission signature of a wind turbine gearbox and generator shaft in service as a pre-requisite for effective condition monitoring". Renewable Energy, 51 (2013) pp. 175-181.

[3] W.Y. Liu, B.P. Tang, J.G. Han, et al; "The structure healthy condition monitoring and fault diagnosis methods in wind turbines: A review" Renewable and Sustainable Energy Reviews, 44 (2015) pp. 466-472.

[4] W. G. Morsi, M. E. El-Hawary; "Fuzzy-Wavelet-Based Electric Power Quality Assessment of Distribution Systems Under Stationary and Non stationary Disturbances", IEEE Transaction Power Delivery, 24 (4) (2009) pp. 2099-2106.
[5] V. Ignatova, P. Granjon, S. Bacha; "Space Vector Method for Voltage Dips and Swells Analysis", IEEE Transaction Power Electronics, 24 (4) (2009) pp. 2054-2061.

[6] R. C. Leborgne, G. Olguin, J. M. Carvalho Filho, et al; "Differences in Voltage Dip Exposure Depending Upon Phase to Phase and Phase to Neutral Monitoring Connections", IEEE Transaction Power Delivery, 22 (2) (2007) pp. 1153-1159.

[7] D. V. N. Ananth, G.V. Nagesh Kumar; "Fault ride-through enhancement using an enhanced field oriented control technique for converters of grid connected DFIG and STATCOM for different types of faults," ISA Transactions. 62 (2016) pp. 2-18.

[8] T. Kamel, Y. Biletskiy, L. Chang;“" Fault Diagnoses for Industrial Grid Connected Converters in the Power Distribution Systems", IEEE Trans. Industrial Electronics, 62 (10) (2015) pp. 6496-6507.

[9] B. Polajzer, G. Stumberger, D. Dolinar; "Detection of voltage sag sources based on the angle and norm changes in the instantaneous current vector written in Clarke's components", Electrical power and Energy Systems, 64 (2015) pp. 967- 976.

[10] G. A. Orcajo, J. M. Cano, M. G. Melero, et al; "Diagnosis of Electrical Distribution Network Short Circuits Based on Voltage Park's Vector", IEEE Transaction Power Delivery, 27 (4) (2012) pp. 1964-1972.

[11] L. Yang, J. Yu, Y. Lai; "Disturbance Source Identification of Voltage Sags Based On Hilbert-Huang Transform", Proceeding in 2010 AsiaPacific Power and Energy Engineering Conference, Chengdu, pp. 1-4, March 2010.

[12] Y. Amirat, Z. Oubrahim, M. Benbouzid; "On phasor estimation for voltage sags detection in a smart grid context", In Proceedings of the 24th IEEE International Symposium on Industrial Electronics (ISIE), 3-5 June, Rio de Janeiro, Brazil, pp. 1351-1356, 2015.

[13] I. Y. H. Gu, N. Ernberg, E. Styvaktakiset al; "A statistical-based sequential method for fast online detection of fault-induced voltage dips", IEEE Trans Power Delivery.19 (2) (2004), pp. 497 - 504.

[14] Y. Amirat, M. Benbouzid, T. Wang et al.; "An Ensemble Empirical Mode Decomposition Approach for Voltage Sag Detection in a Smart Grid Context", International Review of Electrical Engineering, 8 (5) (2013) pp. 1503-1508.

[15] M. Benbouzid, B. Beltran, Y. Amirat, et al; "Second-order sliding mode control for DFIG-based wind turbines fault ride-through capability enhancement", ISA Transactions. 53 (2014) pp. 827-833.

[16] R. Pena, J.C. Clare, G.M. Asher; "Doubly Fed Induction Generator using Back-to-Back PWM Converters and its Application to Variable Speed Wind Energy Generation", IET Electric Power Application, 143(3) (2002) pp. 231- 241.

[17] A. Adouni, D. Chariag, D. Diallo, M. Ben Hamed, L. Sbita; "FDI based on Artificial Neural Network for Low-Voltage-Ride-Through in DFIG-based Wind Turbine“, Elsevier, ISA Transactions, Vol. 64, September 2016, Pages 353-364.

[18] A. Adouni, D. Diallo, L. Sbita; "Current vector trajectory analysis for dip voltage fault detection and identification: Application to wind generator turbine." Proceeding in IEEE International Conference on Industrial Technology (ICIT), (2015), Pages. 3226-3231.

[19] J. Harmouche, C. Delpha, D. Diallo, Y.L. Bihan; "Statistical approach for non-destructive incipient damage detection and characterization using Kullback-Leibler Divergence," IEEE Transactions on Reliability, Volume: 65, Issue: 3, Pages: 1360 - 1368, 2016. 